\title{
Investigation of the Quality and Performance of Organic Solar Cells by Thermographic Imaging
}

\author{
R. Öttking ${ }^{1}$, R. Rösch ${ }^{1}$, M. Seeland ${ }^{1}$, B. Muhsin ${ }^{1}$, K.-R. Eberhard ${ }^{1}$, D. Fluhr ${ }^{1}$, H. \\ Hoppe $^{1}$ \\ ${ }^{1}$ Institute of Physics, Technische Universität IImenau, 98693 IImenau, Germany
}

Organic solar cells are promising candidates for future photovoltaic applications with benefits due to their low production costs, flexibility, conformity, color and wide-range applicability. Presently, efficiencies of approx. 12\% [1] make organic solar cells suitable for commercial applications. The necessary size-upscale, alas, cause severe problems in terms of dissipative losses of several kinds from inside as well as outside the photoactive polymer layer. In order to solve these problems, all possibilities of improvement concerning choice of materials/material combinations, processing and geometrical design have to be considered [2]. The key to this is a deep inside understanding of the underlying physical mechanism and their interplay. Here, the essential first step is to quantitatively represent the losses on the geometrical design. This is where thermographic imaging as a fast and effective tool for the measurement of dissipative losses comes into play. Thermographic imaging, as in dark or illuminated lock-in themography (DLIT/ILIT) is excellently suitable to represent the aforementioned losses under operating conditions [3-5]. Empowered by the lock-in technology, dissipative losses appear instantaneously in their geometrical distribution.

Figure 1 presents the DLIT image of an organic solar cell excited under forward bias (taken from [6]). In addition to the strong heat pattern in the $2.5 \mathrm{~mm}$ wide active layer area, there is a weak pattern in the further course of the device in the vicinity of the contacting electrode (right hand side of the active layer. On the basis of the figure, losses with strong localisation are visible as well as weaker patterns in the vicinity. By complementary measurements and modelling calculations the losses can be traced back to the current profile of the organic solar cell. An example of this is the microdiode model (see, e.g. [7]) suitable to calculate various physical properties to the loss and current patterns of the devices. In particular, the effect of "current crowding" at the edges of the active layer is assumed to lead to loss patterns of the kind presented in figure 1.

Further understanding of the physical properties is necessary to improve the performance in order to meet the requirements for upscaling of organic solar cells to technological relevant modules. Thermographic imaging has already demonstrated to be a valuable tool for the measurement of a wide range of their physical properties and will certainly prove itself to be of even larger importance once various material combinations, processing methods and design variations are to be investigated. 


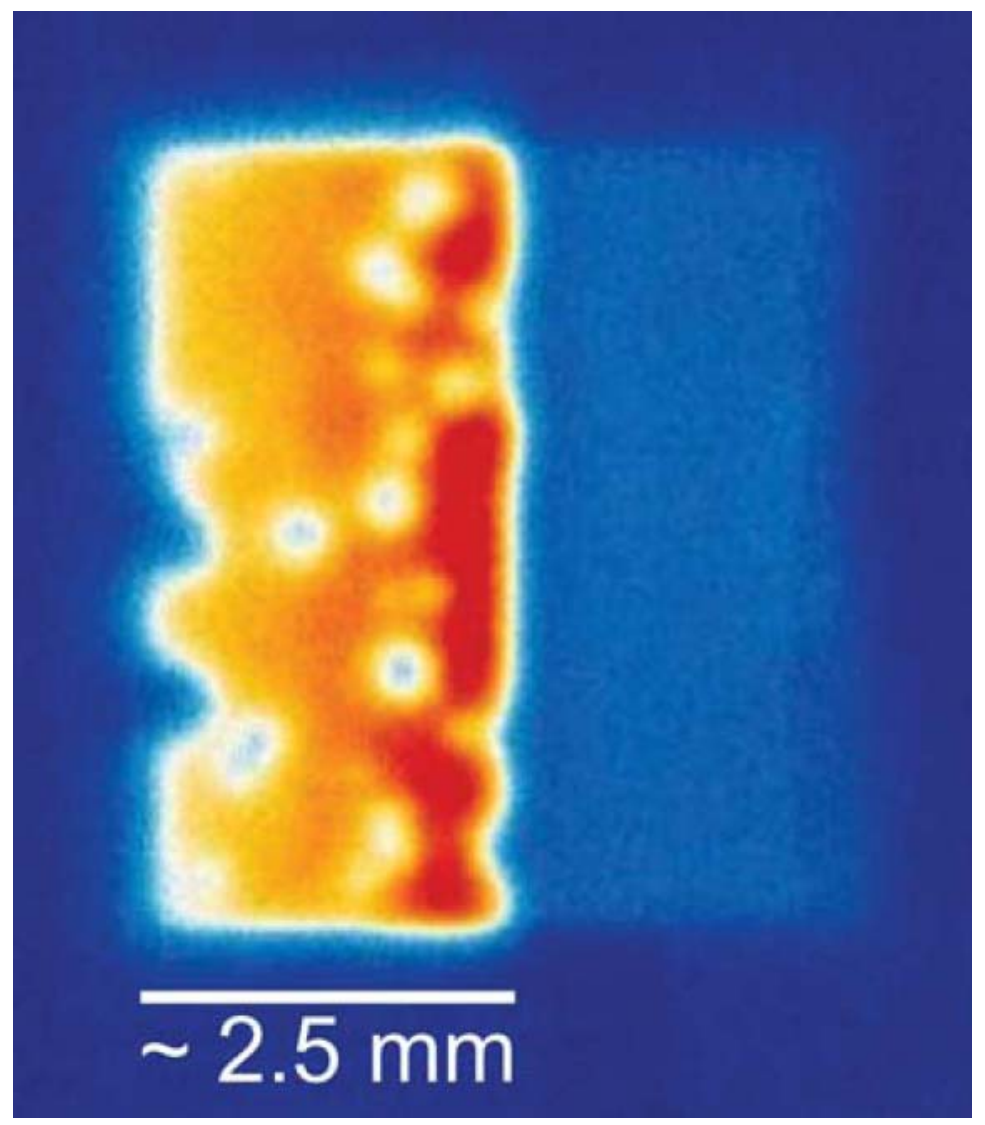

Figure 1: DLIT image of an organic solar cell excited under forward bias. In addition to the strong heat pattern in the $2.5 \mathrm{~mm}$ wide active layer area, there is a weak pattern in the further course of the device in the vicinity of the contacting electrode.

\section{References:}

[1] http://www.heliatek.com/newscenter

[2] H. Hoppe, M. Seeland, B. Muhsin: Solar Energy Materials \& Solar Cells 97, 119 (2012)

[3] H.Hoppe, J. Bachmann, B. Muhsin et al.: J. Appl. Phys. 107, 014505 (2010)

[4] J. Bachmann, C. Buerhop-Lutz, C. Deibel et al.: Solar Energy Materials \& Solar Cells 94, 642 (2010)

[5] J. Bachmann, C. Buerhop-Lutz, R. Steim et al.: Solar Energy Materials \& Solar Cells 101, 176 (2012)

[6] R. Rösch, D.M. Tanenbaum, M. Jørgensen et al.: Energy Environ. Sci. 5, 6521 (2012)

[7] M. Seeland, R. Rösch, H. Hoppe: J. Appl. Phys. 111, 024505 (2012) 